\title{
Application of detection probabilities to the design of amphibian monitoring programs in temporary ponds
}

\author{
Carola Gómez-Rodríguez ${ }^{1, *}$, Antoine Guisan², Carmen Díaz-Paniagua ${ }^{1}$ \& \\ Javier Bustamante ${ }^{1,3}$
}

1) Department of Wetland Ecology, Estación Biológica de Doñana, CSIC, C/Américo Vespucio s/n, ES-41092 Sevilla, Spain (*corresponding author's e-mail: e-mail: carola@ebd.csic.es)

2) Department of Ecology and Evolution, University of Lausanne, $\mathrm{CH}-1015$ Lausanne, Switzerland

3) Remote Sensing and GIS Lab (LAST-EBD), Estación Biológica de Doñana, CSIC, C/ Américo Vespucio s/n, ES-41092 Sevilla, Spain

Received 5 Mar. 2010, revised version received 26 May 2010, accepted 2 July 2010

Gómez-Rodríguez, C., Guisan, A., Díaz-Paniagua, C. \& Bustamante, J. 2010: Application of detection probabilities to the design of amphibian monitoring programs in temporary ponds. Ann. Zool. Fennici 47: 306-322.

Failure to detect a species in an area where it is present is a major source of error in biological surveys. We assessed whether it is possible to optimize single-visit biological monitoring surveys of highly dynamic freshwater ecosystems by framing them a priori within a particular period of time. Alternatively, we also searched for the optimal number of visits and when they should be conducted. We developed single-species occupancy models to estimate the monthly probability of detection of pond-breeding amphibians during a four-year monitoring program. Our results revealed that detection probability was species-specific and changed among sampling visits within a breeding season and also among breeding seasons. Thereby, the optimization of biological surveys with minimal survey effort (a single visit) is not feasible as it proves impossible to select $a$ priori an adequate sampling period that remains robust across years. Alternatively, a two-survey combination at the beginning of the sampling season yielded optimal results and constituted an acceptable compromise between sampling efficacy and survey effort. Our study provides evidence of the variability and uncertainty that likely affects the efficacy of monitoring surveys, highlighting the need of repeated sampling in both ecological studies and conservation management.

\section{Introduction}

A common goal of monitoring programs is to assess the spatial distribution of biological diversity (Yoccoz et al. 2001). Typically, this is measured as the fraction of sampling units in a landscape where a target species is present (occupancy). A major source of error in any biological survey, and hence a potential bias of occupancy metrics, is the failure to detect a species in an area where it is actually present (Yoccoz et al. 2001, Pollock et al. 2002, Pellet $\&$ Schmidt 2005, Schmidt 2005). While presence may be confirmed by detecting the species at a site, it is not possible to verify whether a species is actually absent (MacKenzie 2005, MacKenzie 
et al. 2006). Non-detection of a species may result either from the species being genuinely absent or from the species being present at the site but undetected during the survey (MacKenzie 2005, MacKenzie et al. 2006). Boulinier et al. (1998) define the detectability of a species "as the probability of detecting at least one individual of a given species in a particular sampling effort, given that individuals of the species are present in the area of interest during the sampling session". Since observed absences do not necessarily represent real absences, the probability of detecting a target species (species detectability) conditions the representativeness of a biological survey and thereby the reliability of absence records and their usefulness. For that reason, species detectability should be explicitly contemplated in the design of any monitoring program, especially when species detectability changes over time and, consequently, the representativeness of population surveys and reliability of absence data depend on the date of survey.

Optimal survey design seeks the maximization of statistical power while minimizing financial costs (Field et al. 2005). To improve statistical power, we should avoid non-detection errors or, at least, reduce the probability that we may miss a species when present (i.e. increase the probability of detection). To do this, we may follow two schemes: to estimate occupancy while explicitly accounting for the imperfect detection of the species, or to efficiently allocate the survey effort as a way to minimize the possibility of a false absence. Theoretically, the most robust approach is the incorporation of detection probability into the estimates of population occupancy (MacKenzie 2005, MacKenzie et al. 2006). However, this requires temporal replication at sampling sites (MacKenzie et al. 2002, MacKenzie et al. 2006) and hence it increases costs. A less expensive alternative would be the application of information on detectability from other times or places to know a priori how to achieve a desired level of precision for a minimum survey effort. For instance, we may use data from detection probabilities to determine the minimum effort required to represent a population (De Solla et al. 2005, Pellet \& Schmidt 2005) or to time the sampling visits in order to maximize the detection probability (MacKenzie \& Royle 2005, De Solla et al. 2006).
MacKenzie et al. (2006) provided a statistical method to estimate both the occupancy and detectability parameters simultaneously. This method enables inclusion of habitat covariates. Thereby, we may ascertain whether a particular habitat characteristic favours the presence of a species or it just facilitates its detection. Moreover, we may also evaluate if the probability of detecting a species changes among sampling visits or, on the contrary, it is more likely that it remains constant over time.

Occupancy estimation methods are not widely used by herpetologists and most studies rely on unadjusted count data (Schmidt 2003, 2004, Mazerolle et al. 2007). Many amphibians are secretive or cryptic species and have low detectability (Mazerolle et al. 2007). Detectability is also variable among species (i.e. Bailey et al. 2004, De Solla et al. 2006). Moreover, a given species may also differ in its detectability within a given breeding season or among breeding seasons (De Solla et al. 2005, De Solla et al. 2006). Hence, detectability is not a trait of a species (Mazerolle et al. 2007). Moreover, the detectability of a species widely depends on the survey method used (Schmidt 2004, De Solla et al. 2005, MacKenzie et al. 2006, Gunzburger 2007). For that reason, we should extrapolate literature data with caution (i.e. probability values, influence of environmental factors, and the like). Most previous studies were based on acoustic activity (MacKenzie et al. 2002, De Solla et al. 2005, De Solla et al. 2006) or on observations on terrestrial salamanders (Bailey et al. 2004, Williams \& Berkson 2004). In sum, despite imperfect detectability is assumed for amphibians, few studies evaluated the efficiency of amphibian surveys, the reliability of the absence data recorded and, thereby, its usefulness for population monitoring or diversity assessments. This would be of special relevance in monitoring programs based on a single or few visits, as is the case today with many regional and national programs which aim to reduce field costs. In this type of monitoring program, if species detectability in the particular month of survey is low, we should question the usefulness of the data collected.

In this study, we assessed the usefulness of occupancy models to improve a monitoring 

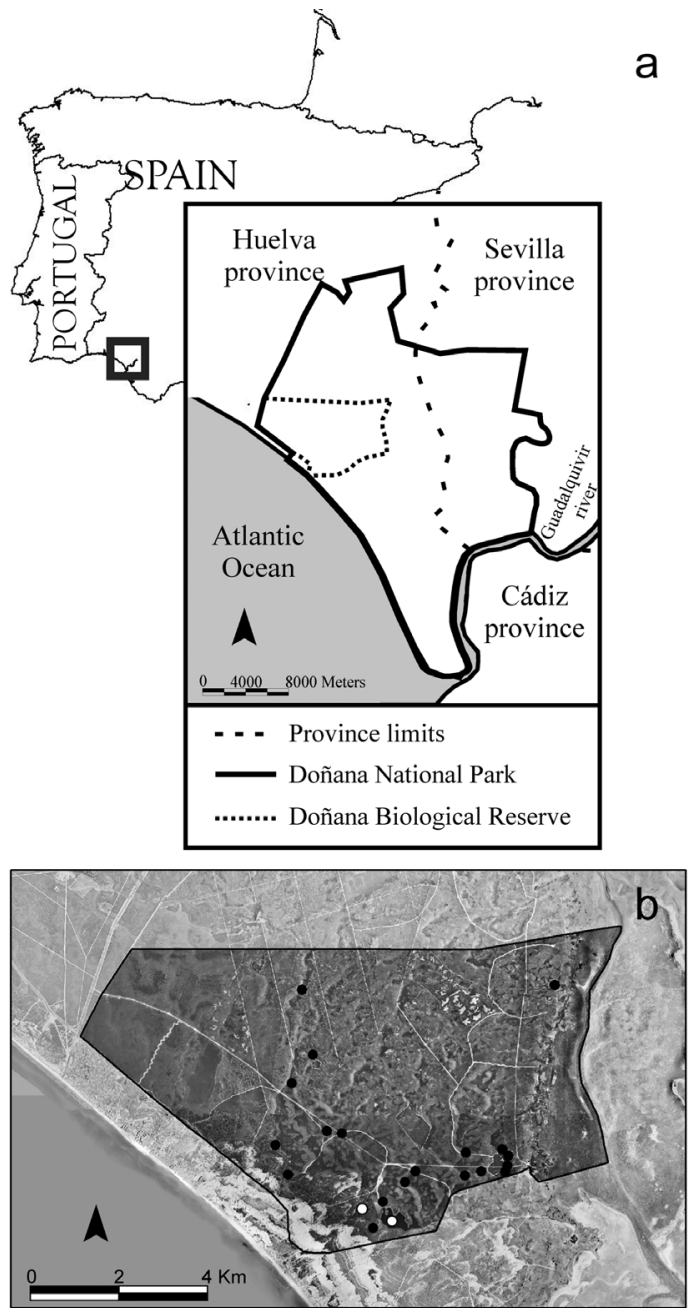

Fig. 1. (a) Location of Doñana National Park in southwestern Spain, and (b) ortophotography of the study area. Solid line delimits the Doñana Biological Reserve, and dots show the location of permanent (white dots) and temporary (black dots) study ponds.

program in a highly temporally variable system, an amphibian community breeding in Mediterranean temporary ponds. We were interested in evaluating the adequacy of single-visit monitoring programs to represent the community and when they should be conducted. Hence, we evaluated whether there is a sampling date when the probability of detecting all species is highest. Alternatively, we also searched for the optimal combination of visits (number of visits and sampling dates). In ecological surveys, the allocation of the survey effort requires a trade-off between minimizing the chance of false absences and maximizing the efficiency of the survey given budgetary or time constraints (Garrard et al. 2008). For each species, we built occupancy models to assess if detectability was constant or varied over time within a breeding season or among seasons as well as to evaluate its relationship with habitat variables. We question the efficacy of single-visit monitoring programs in this type of ecosystem, asking more particularly whether efficacy can be gained by framing the sampling visit within a particular period of time to increase species detectability.

\section{Material and methods}

\section{Study area}

The study was conducted at the Doñana Biological Reserve (Fig. 1), an area of 6794 hectares within the Doñana National Park, in southwestern Spain (see Siljeström et al. 1994 for a geo-morphological description). The dominant vegetation in this area is Mediterranean scrub (Halimio halimifolii-Stauracanthetum genistoides and Erico scopariae-Ulicetum australis as defined by Rivas-Martínez et al. 1980) and isolated patches of pine (Pinus pinea) and juniper forests (Juniperus phoenicea). In the sandy area of the Park, many temporary ponds of natural origin flood during the rainy season (see Gómez-Rodríguez et al. 2008). The area also includes two extensive permanent ponds of natural origin.

For this study, we chose the two permanent ponds and 19 temporary ponds covering a wide hydroperiod gradient in the study area. Permanent ponds sizes were 6.7 and 28.8 ha. Temporary ponds varied in maximum surface area (0.024-5.25 ha) and hydroperiod [2003 hydroperiod: mean value $=6.2$ months, range = 4-9 months; 2006 hydroperiod: mean value $=2.5$ months, range $=1-4$ months (a detailed description of the temporary ponds can be found in Gómez-Rodríguez et al. 2009). In these particular ponds, nine amphibian species were detected in a previous study (Gómez-Rodríguez et al. 2009): Bufo bufo, Bufo calamita, Pelobates cultripes, Discoglossus galganoi, Pelophy- 
lax perezi, Hyla meridionalis, Pleurodeles waltl, Triturus pygmaeus and Lissotriton boscai. Two more species occur in the Doñana National Park, but their main breeding habitats are not ponds: Alytes cisternasii, a species that breeds in ephemeral streams in the north of the Park; and Pelodytes ibericus, mainly associated with marshes. Amphibian species show a temporal segregation in their breeding season (Díaz-Paniagua 1988, Díaz-Paniagua et al. 2005) although all of them may be detected as larvae in March and, except $P$. perezi, also in February and April (Díaz-Paniagua et al. 2005).

\section{Field sampling}

We estimated the maximum sizes of ponds by delineating them on aerial orthophotos (Junta de Andalucía 2003) with ArcView GIS 3.2, and subsequent verification in the field. To compute a pond annual hydroperiod, each pond was visited monthly to record when it filled in and when it dried out. A pond hydroperiod was defined as the number of months the pond was flooded. Accurate hydroperiod data were not available for 2003-2004 (hereafter referred to as 2004, and the same applies to the rest of the seasons) because not all ponds could be visited monthly. However, approximate values were available for some ponds and they were highly similar to hydroperiod values for 2003. So, we assumed the hydroperiod values for 2004 to be the same as those for 2003. Ponds did not flood in 2005 and, thus, this year was excluded from this study.

Amphibian monitoring consisted of intensive sampling once a month during each breeding season: February-May 2003, January-May 2004 and March-May 2006. Monthly surveys were adequate to detect the breeding of all species since the time between egg-laying and leaving the pond as metamorphs is higher than one month for all species (Díaz-Paniagua et al. 2005). Some ponds could not be sampled in certain years: two ponds were not accessible in 2004 (number of ponds in $2004=19$ ) and two different ponds were flooded for less than one month in 2006 (number of ponds in $2006=19$ ). In 2003, one pond was accessible only in May, and since no individuals were found, it was also excluded from the study (number of ponds in $2003=20$ ).

We used dipnetting techniques (Heyer et al. 1994) to collect and to identify larvae to species level in situ (referred hereafter as "larval sampling"). Sampling units consisted of three consecutive dipnet sweeps on a stretch of approx. $1.5 \mathrm{~m}$ length. We counted the number of larvae captured in each sampling unit and then released them back. Sampling units were separated by a minimum of five metres to avoid interference between surveys. For most ponds, we set 12 sampling units per month. Small ponds were sampled in proportion to their size, so the number of sampling units could decrease to guarantee minimum separation $(5 \mathrm{~m})$. In large ponds we tried to sample all different microhabitats, increasing the number of sampling units performed as needed to cover the environmental heterogeneity. In 2003 and 2004, pond size was large enough to conduct 12 sampling units in most ponds $(12.8 \pm 4.7$ [SD] in 2003; $12.0 \pm 0.3$ [SD] in 2004). However, in 2006, pond size was smaller due to scarce rainfall and, thereby, the number of sampling units was reduced in most ponds $(9.0 \pm 5.8$ [SD] in 2006).

Larval sampling was complemented with visual surveys in and around the pond to detect eggs, larvae, and metamorphic individuals.

\section{Data analysis}

To depict each species phenology, we quantified its relative abundance and the number of ponds it was observed in (naïve occupancy) in each month. We also quantified the number of species detected across the entire study area (species richness) in each month. For each species, the monthly relative abundance was computed from the "larval sampling" data as the number of larvae collected per sampling unit, using only occupied ponds.

To simultaneously estimate the single-visit probability of detection $(p)$ and the proportion of occupied ponds (POP), we developed single-species occupancy models (MacKenzie et al. 2002, MacKenzie et al. 2006) with the PRESENCE program (MacKenzie et al. 2002). PRESENCE uses standard maximum likelihood techniques 
to obtain estimates of model parameters ( $p$ and POP) and requires at least two sampling events per breeding season in a set of ponds. The estimated POP differs from the naïve occupancy when the organisms are imperfectly detected (they are not always detected when present at a site). Actually, single-species occupancy models estimate the probability that a site within a group of sites is occupied (probability of occupancy $[\Psi]$ ). In this study, the estimated POP will be equal to the probability of occupancy. The single-visit detection probability $(p)$ of a species is the probability that it will be detected at a pond in one sampling visit, given that the species breeds in the pond. Theoretically, both POP and $p$ may be constant across all ponds or may vary in accordance with habitat characteristics. Besides, POP is assumed not to vary during the sampling season ("closed occupancy status"), whereas $p$ may be constant or visit-specific. However, in the study area, POP may change during the breeding season depending on each species' phenology (i.e. the pond is not occupied before the date of arrival in pond, which may be delayed in the breeding season). So, in this study, the assumption of "closed occupancy status" is a practical one that enables the assessment of differences in sampling efficacy for a given species (measured as its detection probability) depending on the month of survey. In other words, we assume that if a species occupies a pond in a given breeding season, we should be able to detect it whenever we survey that pond in that season (i.e. in any sampling visit). Hence, the probability of detection will be null, evidencing a very low sampling efficacy, if the species has not reached the pond (or already left it) when the survey is conducted.

For each species and breeding season, we developed single-species occupancy models from the sequence of detections and non-detections of the target species in each pond over multiple sampling visits (detection histories). We developed a set of six a priori candidate models, each representing an alternative hypothesis, to assess if the probability of occupancy was constant or varied in accordance with habitat characteristics known to be critical for amphibians, such as hydroperiod (Wellborn et al. 1996, Snodgrass et al. 2000, Werner et al. 2007) or pond size (Laan \& Verboom 1990, Beja \& Alcazar 2003, Werner et al. 2007) and to assess if the single-visit probability of detection was constant, visit-specific or varied in accordance with habitat characteristics such as hydroperiod or pond size (Table 1). We examined the relationship between the probability of detection and both habitat characteristics (pond size and hydroperiod) because they account for the spatial and temporal dimension of ponds, respectively. In other words, we hypothesize that they may condition the probability of spatial and temporal coincidence between individuals and sampling visits (i.e. the longer the duration of a pond, the lower the probability that a given sampling visit is inevitably timed to the larval period of a species). All models included intercepts for both $\Psi$ and $p$. We had not constructed a global

Table 1. Set of candidate models evaluated. $\Psi$ is the probability of occupancy and $p$ is the probability of detection. Covariates for each parameter are given in parentheses. Dots indicate constants.

\begin{tabular}{|c|c|}
\hline Model & Hypothesis \\
\hline$\Psi(),. p()$. & $\begin{array}{l}\text { Probability of occupancy constant across ponds. } \\
\text { Probability of detection constant across ponds and visits. }\end{array}$ \\
\hline$\Psi(),$.$p (month)$ & $\begin{array}{l}\text { Probability of occupancy constant across ponds. } \\
\text { Probability of detection constant across ponds but varies across visits. }\end{array}$ \\
\hline$\Psi($ area $), p()$. & $\begin{array}{l}\text { Probability of occupancy varies in accordance with pond size. } \\
\text { Probability of detection constant across ponds and visits. }\end{array}$ \\
\hline$\Psi$ (hydro), $p()$. & $\begin{array}{l}\text { Probability of occupancy varies in accordance with pond hydroperiod. } \\
\text { Probability of detection constant across ponds and visits. }\end{array}$ \\
\hline$\Psi(),. p($ area $)$ & $\begin{array}{l}\text { Probability of occupancy constant across ponds. } \\
\text { Probability of detection constant across visits but varies in accordance with pond size. }\end{array}$ \\
\hline$\Psi(),$.$p (hydro)$ & $\begin{array}{l}\text { Probability of occupancy constant across ponds. } \\
\text { Probability of detection constant across visits but varies in accordance with pond hydroperiod. }\end{array}$ \\
\hline
\end{tabular}


model, including all parameters, since it would have included far more parameters than needed given our data (20 cases at most). Model covariates (hydroperiod and pond size) were standardized to $Z$ scores (mean value $=0, S D=1$ ) as recommended by Donovan and Hines (2007) when the range of the covariate is over several orders of magnitude because the numerical optimization algorithm may fail to find the correct parameter estimates. To avoid problems with the standard error estimation in the visit-specific $p$ model $[\Psi(),$.$p (month)], we manually fixed the$ detection probability for a given sampling visit to be 0 or 1 if the species was not detected in any pond or detected in all the occupied ponds, respectively. When multiple models are to be considered, it is generally recommended that the global model is assessed for lack of fit (MacKenzie et al. 2006). Since there was no global model in this study, each model was checked for lack-of-fit using parametric bootstrapping (1000 samples) to determine whether the observed value of Pearson's chi-square statistics was unusually large (see MacKenzie \& Bailey 2004). Since only some models showed lack-of-fit, those models were discarded when computing model-averaged values of parameters. Substantial lack-of-fit may lead to inaccurate inferences, either in terms of bias or in terms of precision (MacKenzie et al. 2006). Similarly, we had to discard model outputs when we could not reach algorithm convergence in the iterative search for the maximum likelihood.

We followed an Information Theoretic Approach, based on second-order Akaike's Information Criterion $\left(\mathrm{AIC}_{\mathrm{c}}\right)$, to model selection and multimodel inference of parameters (see Burnham \& Anderson 2002). So, estimates of the parameters of interest ( $p$ and $\Psi$ ) were based on the entire set of models rather than on the one selected as best. Model-averaged estimates are more precise and are less biased as compared with estimates from a selected best model and are especially useful if no model is clearly best (Burnham \& Anderson 2002). Our approach for model selection consisted of two steps: First, we ranked models according to their AIC $_{c}$ values in order to obtain Akaike's model weights $(\omega)$, which quantifies the uncertainty that each model is the target best model (see Burnham \& Anderson 2002). We used AIC rather than AIC because it is recommended when the ratio between sample size and number of model parameters is smaller than 40 (Burnham \& Anderson 2002). For each model, we also computed the averaged value of Akaike's weight for the entire study period, for each breeding season and for each species, in order to assess its "global" relevance. Second, we used model weights to compute the model-averaged estimates of parameters ( $p$ and $\Psi$ ) and their unconditional standard errors, which incorporate model selection uncertainty into estimates of precision (see Burnham \& Anderson 2002). We could not compute a model-averaged probability of detection when the visit-specific $p$ model was the one largely "best" supported by the data (lowest ranked model and with large Akaike's weight), since it was the only model including those parameters. Models that did not fit the data and parameter values that did not converge were excluded from model-averaging.

We computed the annual probability of detection (annual $p^{*}$ ), to assess the probability that the species was detected after the $k$ times (sampling visits) the pond was surveyed that year, by applying the formula provided by MacKenzie et al. (2006):

$$
p^{*}=1-\prod_{i=1}^{k}\left(1-p_{i}\right)
$$

To assess the optimal number of surveys and when they should be conducted, we compared the monthly probabilities of detection with the probability of detecting a species after two and three surveys, using repeated measures ANOVA with a posthoc Fisher test (Statistica Software). Using the aforementioned formula, we computed the probability of detecting each species: (i) after two consecutive surveys, at the beginning of the sampling season (i.e. February and March); (ii) after two consecutive surveys, in the middle of the sampling season (i.e. March and April); (iii) after two consecutive surveys, at the end of the sampling season (i.e. March and May); (iv) after two alternative surveys, at the beginning of the sampling season (i.e. February and April); (v) after two alternative surveys, at the end of the sampling season (i.e. March and May); (vi) after three consecutive surveys at the beginning of 

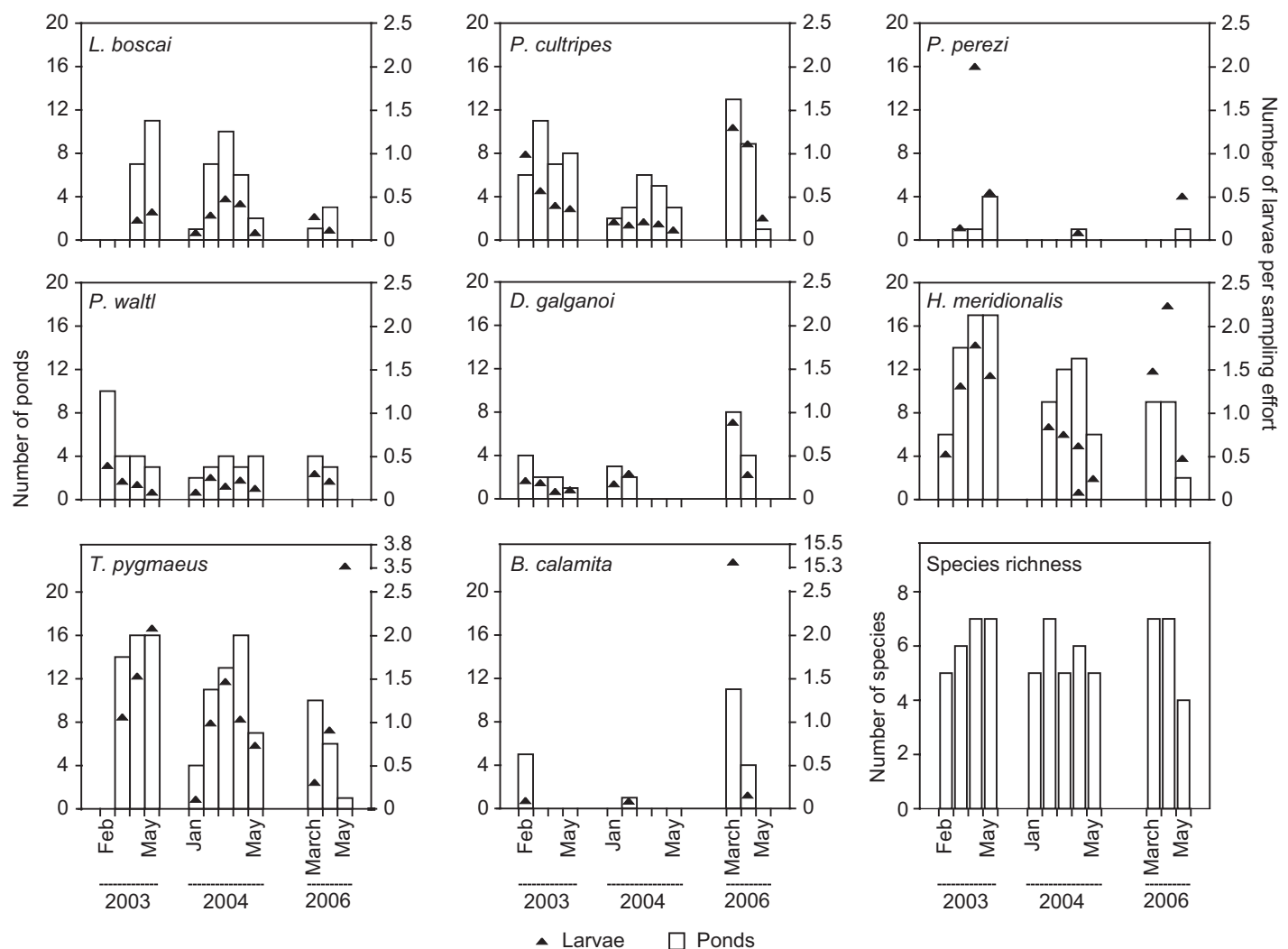

Fig. 2. The number of ponds a species was observed to occupy (monthly observed POP), its monthly relative abundance (number of larvae per sampling effort) and the number of species detected in the entire study area (species richness).

the sampling season (i.e. February, March and April), and (vii) after three consecutive surveys at the end of the sampling season (i.e. March, April and May). Data for January 2004 were excluded from the analyses. Since only three months were sampled in 2006, there was no information for the end of the sampling season.

\section{Results}

\section{Species phenology}

We detected all pond-breeding amphibian species except B. bufo. All species bred in each season, although we did not detect all species during any single sampling visit (Fig. 2). The observed number of species varied among sampling visits, and was lowest (four species) in May 2006, whereas the largest number (seven species) was found at least during one sampling visit in each breeding season. Pelobates cultripes was the only species that was detected during all sampling visits. Bufo calamita was detected only during one sampling visit in 2003 and one in 2004; while P. perezi in 2004 and 2006 and $D$. galganoi was observed during less than $50 \%$ of the sampling visits in 2004. Bufo calamita and $D$. galganoi were observed at the beginning of their breeding seasons, whereas $P$. perezi was recorded at the end of its breeding seasons. The other species were detected, at least in one pond, during most of the sampling visits.

The monthly relative abundance and the number of ponds a species was observed to occupy in a given month (monthly naïve occupancy) widely varied among sampling visits (Fig. 2). The maximum monthly naïve occupancy did not equal the annual naïve occupancy for most species and breeding seasons (Table 2). 


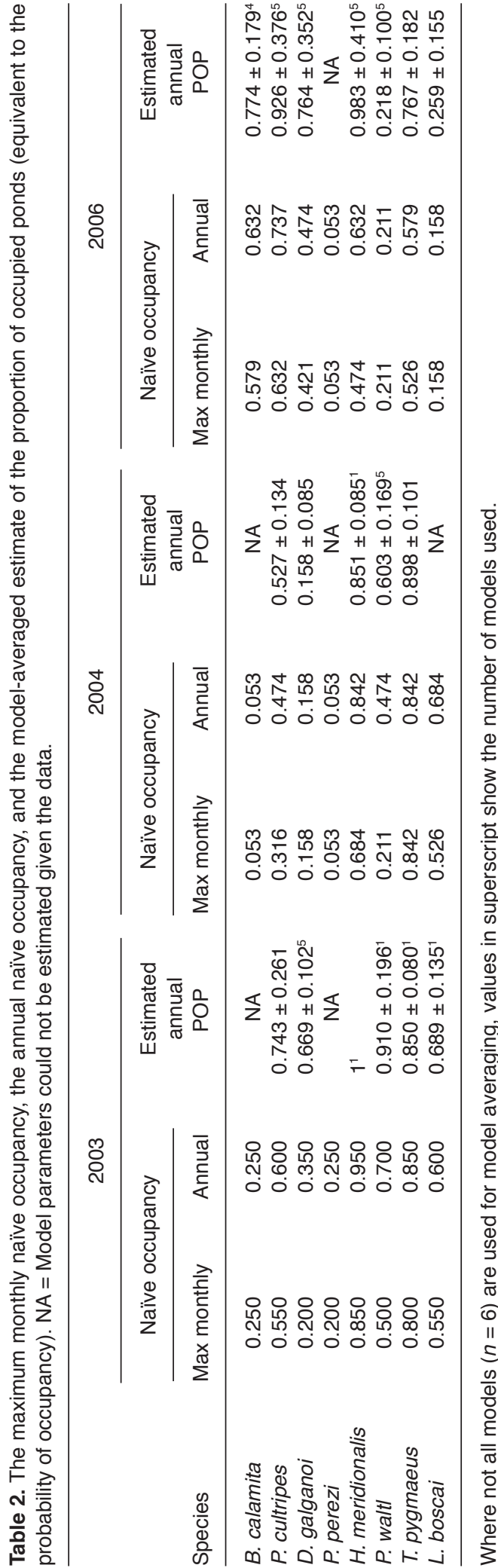

So, we could not identify all the occupied ponds if we surveyed only in the month when the maximum monthly occupancy was recorded.

\section{Single-species occupancy models}

We developed single-species occupancy models for all species and breeding seasons (see Appendix for details) except for B. calamita in 2003 and 2004 and for P. perezi in 2004 and 2006, since they were detected only during one sampling visit and thus lacked the necessary repeated sampling. For most of the species and breeding seasons, we computed model-averaged estimates of parameters from a set of candidate models with a summed weight of evidence above 0.750 . We could not estimate model parameters ( $p$ and $\Psi$ ) for $L$. boscai in 2004 because no model fitted the data. Neither could we estimate model parameters for P. perezi in 2003 because of very low support for the models that fitted the data (summed models $\omega<0.050$ ) (see Appendix for details).

Taking into account total Akaike's weight of each candidate model across all species and seasons, the model considering the probability of detection variable among visits [visit-specific $p$ model: $\Psi(),$.$p (month)] obtained the greatest$ support given the data (Table 3). The second "best" model was the one considering the probability of detection constant across ponds and sampling visits, and the probability of occupancy to vary in accordance with pond size [ $\Psi$ (area), $p()$.$] . The same pattern was observed when we$ considered total Akaike's weight of each candidate model across all species in a given sampling season. At the species level, considering total Akaike's weight across seasons, the visitspecific $p$ model showed the highest support for all species except $P$. cultripes and $P$. perezi. For any given species, we observed differences in model ranking and model weights among breeding seasons, indicating that there was not a "best supported hypothesis" valid for all the breeding seasons (see Appendix for details). For example, we should consider the detection probability of $H$. meridionalis and $T$. pygmaeus variable among sampling visits in 2003, since the visitspecific $p$ model was clearly the best supported 
model $(\omega \geq 0.999)$. On the contrary, the same hypothesis received low support for $2006(H$. meridionalis $\omega=0.077 ;$. pygmaeus $\omega=0.019$ ) as compared with the ones assuming $p$ to be constant across sampling visits (see Appendix).

The single-visit probability of detection was highly variable among species (Table 4). In general, the single-visit detection probabilities were moderate for $P$. cultripes and $T$. pygmaeus (mean single-visit $p$ between 0.50 and 0.75 ) and low for the other species (mean single-visit $p$ between 0.25 and 0.50 ). However, the probability of detection was highly variable among seasons and even among sampling visits within a given season, reaching high values for particular months (Table 4). The single-visit probability of detection of all species was below 1 for all sampling visits except for $D$. galganoi in January 2004, P. waltl in March 2006, L. boscai in April 2006 and T. pygmaeus in April and May 2003 and in April 2004. All species except $P$. cultripes were completely undetectable at least during one sampling visit (sampling visits with a null single-visit probability of detection). No single sampling visit showed the highest or the lowest probability of detection for all the species or most of them.

The probability that a given species was detected after the sampling effort conducted during the entire breeding season (annual $p^{*}$ ) was high $\left(p^{*}>0.75\right)$ for all the species except D. galganoi in 2003 (Table 4). The annual $p^{*}$ was very high $\left(p^{*}>0.95\right)$, at least in one breed- ing season, for all species except B. calamita, which lacked data in two seasons (Table 4). Due to such high annual probabilities of detection, the observed and estimated values of occupancy were similar for most species and breeding seasons except $D$. galganoi in 2003 (Table 2).

We observed significant differences in the probability of detection depending on the number of surveys and the time when they were conducted (repeated measures ANOVA: $F_{10,100}=$ $5.445, p<0.0001$; Fig. 3). A posthoc Fisher test evidenced that three surveys, both at the beginning and at the end of the sampling season, and two alternative surveys at the beginning of the sampling season were significantly better than any one survey $(p<0.05)$. Besides, there were no significant differences among those three approaches. The rest of the two-survey combinations were better than some one-survey, but not all. Thereby, the combination of two alternative surveys at the beginning of the sampling season was the optimal one, for it was as good as the three-survey combination but required less effort. Two alternative surveys at the beginning of the sampling season yielded cumulative detection probabilities above 0.78 for most species. However, they were not so successful for D. galganoi (2003: $p=0.32,2004: p=0.66$, 2006: $p=0.64$ ), a species always showing low detectability; P. waltl (2003: $p=0.68,2004: p=$ 0.50), L. boscai (2003: $p=0.55,2006: p=0.22)$ and P. cultripes (2004: $p=0.64)$. A combination of surveys rarely yielded detection probabilities

Table 3. Averaged values of Akaike's weight of each candidate model. Values were averaged across all species and seasons (GLOBAL), across all species within a breeding season (YEAR) and across seasons for a given species (SPECIES). Maximum values (averaged best supported hypothesis) are set in boldface.

\begin{tabular}{llcccccc}
\hline & & $\Psi(),. p()$. & $\Psi(),. p($ area $)$ & $\Psi(),. p($ hydro $)$ & $\Psi(),. p($ month) & $\Psi($ area $), p()$. & $\Psi($ hydro $), p()$. \\
\hline GLOBAL & & 0.10 & 0.06 & 0.04 & $\mathbf{0 . 5 5}$ & 0.18 & 0.06 \\
YEAR & 2003 & 0.10 & 0.03 & 0.03 & $\mathbf{0 . 5 8}$ & 0.21 & 0.04 \\
& 2004 & 0.11 & 0.05 & 0.03 & $\mathbf{0 . 5 8}$ & 0.19 & 0.04 \\
SPECIES & B. calamita & 0.10 & 0.10 & 0.05 & $\mathbf{0 . 5 1}$ & 0.14 & 0.09 \\
& P. cultripes & 0.28 & 0.02 & 0.02 & $\mathbf{0 . 8 9}$ & 0.01 & 0.02 \\
& D. galganoi & 0.20 & 0.05 & 0.08 & 0.09 & $\mathbf{0 . 3 5}$ & 0.11 \\
& P. perezi & 0 & 0 & 0.06 & $\mathbf{0 . 5 4}$ & 0.08 & 0.06 \\
& H. meridionalis & 0.06 & 0.02 & 0.03 & 0 & 0.95 & 0.02 \\
& P. walt & 0.05 & 0.01 & 0.01 & $\mathbf{0 . 6 9}$ & 0.08 & 0.14 \\
& T. pygmaeus & 0.05 & 0.20 & 0.03 & $\mathbf{0 . 6 2}$ & 0.25 & 0.04 \\
& L. boscai & 0.02 & 0 & 0.01 & $\mathbf{0 . 6 4}$ & 0.05 & 0.01
\end{tabular}




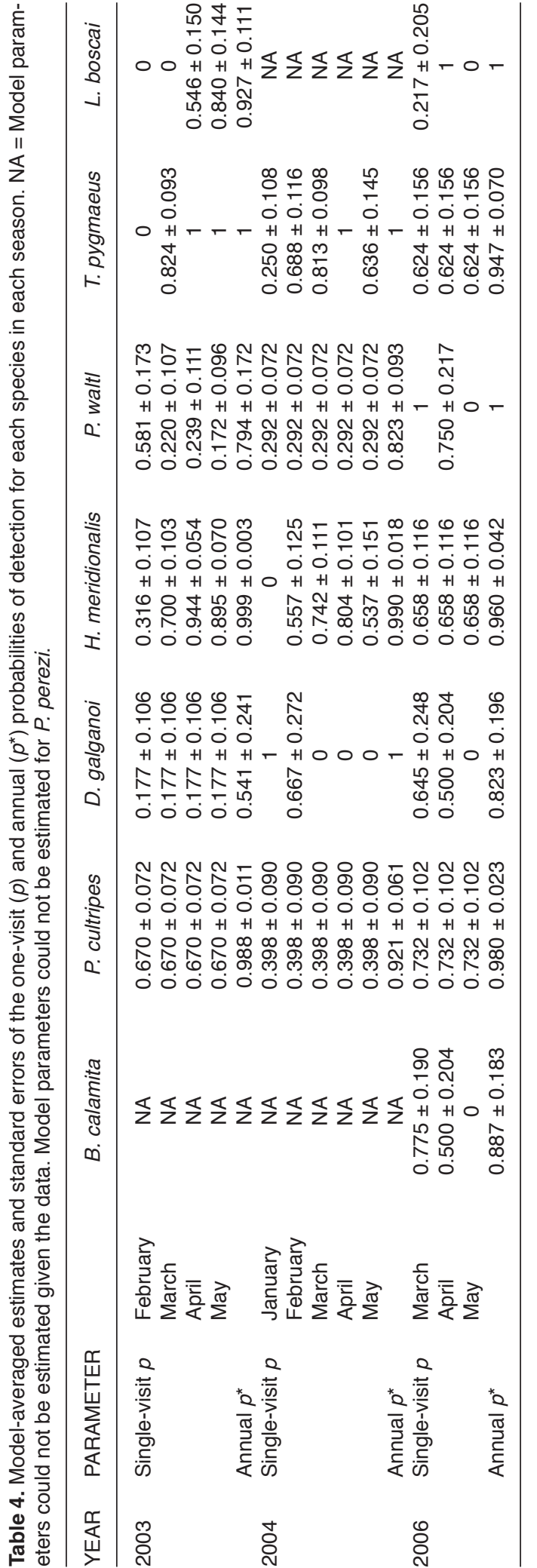

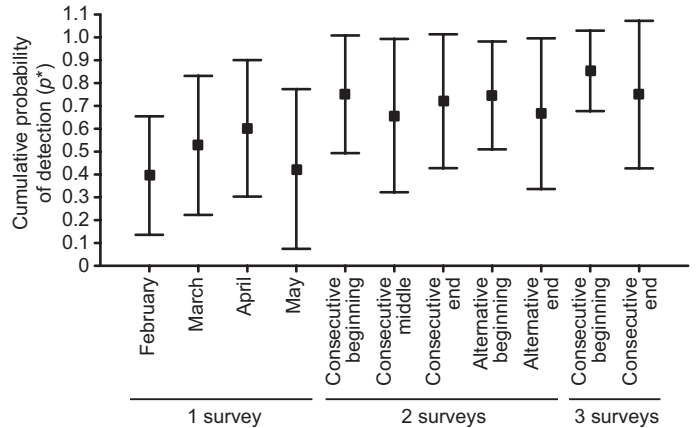

Fig. 3. Mean and standard deviation of the probability of detection after $k$ surveys $(k=1-3)$ conducted in different months. When more than one survey was conducted, values are shown for surveys conducted in consecutive or alternative months and at the beginning, in the middle or at the end of the sampling season.

above 0.78 for these the species, except the case of two alternative surveys at the end of the sampling season in the case of L. boscai in 2003 and 2006 and two consecutive surveys at the beginning of the sampling season for D. galganoi in 2006. Pelobates cultripes required three surveys in 2004 to reach a good probability of detection. Surveying only twice (two alternative surveys at the beginning) yielded worse results than sampling every month, as evidenced by the probability of detection being significantly lower than the annual probability of detection $\left(F_{1,17}=\right.$ $14.688, p=0.001)$.

\section{Discussion}

\section{Heterogeneity of detection probability across time and species}

The occupancy and probability of detection of amphibians were species-specific and, for most species, largely varied among sampling dates within a breeding season and also among breeding seasons. We may distinguish two major causes reducing (or cancelling) the monthly probability of detection of a species in a pond where it breeds: (i) "methodological constraints", due to a low efficacy of the sampling survey to detect the species when it is actually present, and (ii) "phenological constraints", as a species can only be detected in the period 
between the dates of arrival in pond and leaving pond. In this study, a low but non-null detection probability can be attributed to "methodological constraints" as it proves that the species was present in some ponds and, hence, that those sampling visits were timed to the phenology of the species in the area. In that case, increasing the sampling effort (number of sampling units) conducted in each pond would probably have resulted in an increase of the monthly probability of detection. On the contrary, a null value in the probability of detection can be attributed to both "methodological" and/or "phenological" constraints as it may evidence both an extremely low probability of detection (the species was in the ponds but we failed to detect it) or inadequate timing of the sampling visit (being conducted outside the species breeding season, when it was not actually present at the breeding site), respectively. Identifying the causes of low detection probabilities (phenological or methodological) may help improving the sampling efficacy and reducing the proportion of false absences. Hereafter, we use the duality between phenological and methodological constraints as an operational framework to discuss our results.

Applying surveys at breeding sites, we observed inter-specific differences in the probability of detection, which concurs with results from previous studies based on acoustic surveys (De Solla et al. 2005, Pellet \& Schmidt 2005, Schmidt 2005, De Solla et al. 2006, Gooch et al. 2006). For any given species, we also observed that the probability of detection varied within and between years. Both patterns have been reported in previous studies based on acoustic surveys (Schmidt 2005, Gooch et al. 2006) but are lacking for dipnetting surveys, a method frequently used by wetland ecologists. In our study, both phenological and methodological constraints may explain variation in detectability among species and years. Focusing on inter-specific variation, phenological constraints can arise from differences in reproductive strategies (see review in Wells 2007) and timing (Díaz-Paniagua 1992) among species, resulting in different temporal use of ponds and hence with some species being possibly absent in particular months. Methodological constraints can arise from interspecific differences in conspicuousness (Heyer et al. 1994) and abundance, due to the fact that the more abundant a species the easier its detection (Royle \& Nichols 2003, MacKenzie 2005, MacKenzie et al. 2006, Royle 2006). Regarding temporal variation in the detectability of a species, phenological constraints can be related to inter-annual variability in the pattern of breeding in response to variation in abiotic factors, such as the seasonal distribution of rainfall and date of pond flooding (Jakob et al. 2003, Wells 2007) and, within a breeding season, to the characteristics of the reproductive strategy (i.e. long or short larval development) and timing of reproduction of a species (i.e. early breeders or late-breeders). Temporal variation in detection probabilities is also related to methodological constraints, caused by both biotic and abiotic factors. We can attribute the intra-annual differences in detectability to changes in biotic conditions, such as changes in the abundance of a species in a pond. On the other hand, the characteristics of the pond at the time of the survey may also have conditioned the detectability of a species. For instance in 2006, when we observed a generalized increase in the probability of detection, the late pond flooding resulted in smaller pond sizes (personal observation) and hence improved the efficacy of surveys, since effectiveness of dipnetting techniques increases as the size of the pond decreases (Heyer et al. 1994). However, we could not evaluate this hypothesis (i.e. pond size as a temporally variable characteristic) since we related detection probability to constant habitat covariates. Unfortunately, we lacked data on pond characteristics for specific months of survey.

The absence of a "best supported hypothesis" to explain detection probability patterns of a species valid for all the breeding seasons, is in concordance with the temporal variability of amphibian breeding habitats (Gómez-Rodríguez et al. 2009, Gómez-Rodríguez et al. 2010) and amphibian pond assemblages (GómezRodríguez et al. 2010) in the study area. In fact, a similar result was obtained in a previous study that evidenced that habitat model outputs of amphibians were year-specific in the study area (Gómez-Rodríguez et al. 2009). So, inter-annual variation in the model parameters that explained species detectability would be analogous to the 
previously reported inter-annual changes in the relative importance of habitat characteristics to explain species relative abundance or species richness (Gómez-Rodríguez et al. 2009). This study may face two potential limitations: (i) the simultaneous analysis of temporary and permanent ponds, and (ii) the relationship between sampling effort and pond area. In this study, we assumed that the main differences between permanent and temporary ponds were accounted for by the inclusion of the "pond area" and "pond hydroperiod" covariates in the models. However, given the limited relevance of those parameters along with the difficulty to detect amphibian species in permanent ponds (personal observation), it seems that further research, focused solely to permanent ponds, would be advisable. This was not possible in the study area since there are only two permanent ponds. On the other hand, it could be argued that the pond area covariate may be misleading since sampling effort was adjusted to pond size. So, one could expect that the more efficient prospection of smaller ponds (where sampling effort was proportionally higher) would increase species detectability and, thereby, the apparent relevance of pond area to explain species detectability. However, this was not the case and, thus, we can discard any bias due to differences in sampling effort. Similarly, it could be argued that inaccuracy in pond hydroperiod measurements in 2004 may yield biased results. Still, the relevance of hydroperiod was low in model building and similar among years, evidencing that using 2003 data as a surrogate for 2004 hydroperiod is not a critical issue.

\section{Monitoring implications}

We showed the inadequacy of single-visit monitoring programs to get an accurate description of an amphibian community breeding in Mediterranean temporary ponds. The efficacy of amphibian monitoring programs depends highly on the species, the breeding season, and the timing and frequency of sampling visits. We found that the efficacy of a single sampling visit to conduct community-level assessments was very low since not all species overlapped in time, i.e. we did not detect all species in any single sampling visit, and the single-visit probability of detection was moderate or low for many of them in most sampling visits. Besides, although most amphibian species reached an almost perfect detection probability at some point during the breeding season, those moments were not synchronized among species. For that reason, community assessments in a study area are prone to potential biases due to temporal segregation of reproduction (Heyer 1976, Wiest 1982, Wells 2007), a strategy to reduce inter-specific competition in larval communities (Lawler \& Morin 1993, Wells 2007) which has been previously reported in the study area (Díaz-Paniagua 1988, 1992). In specieslevel occupancy studies, a single-visit may be sufficient to evaluate the proportion of occupied ponds (POP) if it is timed when the probability of detection is close to 1 , and hence the monthly observed occupancy equates the annual observed occupancy. However, we recommend that monitoring programs in similar dynamic ecosystems should not be based on a single-visit, since perfect probabilities of detection $(p \approx 1)$ are rarely observed and the best month to survey (highest probability of detection or, at least, highest monthly POP) can differ among years and hence it is hardly predictable from one year to the next. This means that, for most species in the study area, we should be able to predict the onset and the duration of the breeding season based on their reproductive strategy and rainfall input and pattern, but we cannot predict with certainty when a species will occupy the largest number of ponds or when the probability of detection will be highest. An optimal alternative is conducting two surveys in alternative months at the beginning of the sampling season. Conducting alternative surveys reduces potential biases due to temporal segregation in pond usage and, conducting those surveys at the beginning of the sampling season reduces the probability that, when the survey is conducted, species of short larval development may have already metamorphosed, which would make its detection more difficult. This combination of surveys is less satisfactory than surveying every month, but constituted a good compromise between sampling efficacy and sampling effort. However, it should be noted that it might still be deficient for community-level assessments, since three species showed moderate or low cumula- 
tive probabilities of detection in particular years (D. galganoi; L. boscai and P. waltl, the latter only in 2003 and 2004). In fact, detecting these species with a reduced number of surveys is difficult because they were inconspicuous in most sampling visits, probably because they are not abundant in the study ponds. A different study, focused on plant species, has already proved that the number of visits needed to detect easy-to-find species may be lower than the number needed to detect hard-to-find species (Kery et al. 2006).

Occupancy models constitute a powerful tool for assessing the efficacy and optimal timing of faunal monitoring programs. In this study, we showed that the efficacy of amphibian surveys in a Mediterranean pond-breeding community can vary considerably and yield large uncertainty in final occupancy estimates, a finding that could also apply to other taxonomic groups occurring in similar habitats. In such highly dynamic systems, designing a priori an efficient monitoring program is almost impossible without conducting an intensive survey (i.e. multi-visit survey). An insufficient or inappropriate sampling effort will likely only allow detecting the most frequent species, thus missing the ones that breed in a lower number of ponds and erroneously concluding that they are rarer than they actually are. Although knowledge of breeding phenologies is necessary for designing appropriate monitoring and inventory assessments in amphibians (Paton \& Crouch 2002), we should not base the allocation of sampling effort only on the dates of arrival in pond and leaving pond, since this approach may still result in false absences due to imperfect species detectability during the sampling period.

\section{Acknowledgments}

We thank Margarita Florencio Díaz, Alexandre Portheault and Carlos Marfil Daza for assistance with fieldwork. Dr. Kotiaho, Dr. Gómez-Mestre and an anonymous reviewer provided helpful comments that contributed to improve the manuscript. The Spanish Ministry of Science and Innovation and the EU, FEDER program (project REN 200203759/GLO and CGL2006-04458/BOS and Fellowship grant AP-2001-3475 to C.G.-R.) and Junta de Andalucía (Excellence Research Project 932 to C.D.-P. and Excellence ShortStay in University of Lausanne to C.G.-R.) financed this work.

\section{References}

Bailey, L. L., Simons, T. R. \& Pollock, K. H. 2004: Estimating site occupancy and species detection probability parameters for terrestrial salamanders. - Ecological Applications 14: 692-702.

Beja, P. \& Alcazar, R. 2003: Conservation of Mediterranean temporary ponds under agricultural intensification: an evaluation using amphibians. - Biological Conservation 114: 317-326.

Boulinier, T., Nichols, J. D., Sauer, J. R., Hines, J. E. \& Pollock, K. H. 1998: Estimating species richness: The importance of heterogeneity in species detectability. Ecology 79: 1018-1028.

Burnham, K. P. \& Anderson, D. R. 2002: Model selection and multimodel inference: A practical information-theoretic approach. - Springer, New York.

De Solla, S. R., Fernie, K. J., Barrett, G. C. \& Bishop, C. A. 2006: Population trends and calling phenology of anuran populations surveyed in Ontario estimated using acoustic surveys. - Biodiversity and Conservation 15: 3481-3497.

De Solla, S. R., Shirose, L. J., Fernie, K. J., Barrett, G. C., Brousseau, C. S. \& Bishop, C. A. 2005: Effect of sampling effort and species detectability on volunteer based anuran monitoring programs. - Biological Conservation 121: 585-594.

Díaz-Paniagua, C. 1988: Temporal segregation in larval amphibian communities in temporary ponds at a locality in SW Spain. - Amphibia-Reptilia 9: 15-26.

Díaz-Paniagua, C. 1992: Variability in timing of larval season in an amphibian community in SW Spain. - Ecography 15: 267-272.

Díaz-Paniagua, C., Gómez-Rodríguez, C., Portheault, A. \& de Vries, W. 2005: Los anfibios de Doñana. Organismo Autónomo de Parques Nacionales. - Ministerio de Medio Ambiente, Madrid.

Donovan, T. M. \& Hines, J. 2007: Exercises in occupancy modeling and estimation. - Available at www.uvm.edu/ envnr/vtcfwru/spreadsheets/occupancy/occupancy.htm.

Field, S. A., Tyre, A. J. \& Possingham, H. P. 2005: Optimizing allocation of monitoring effort under economic and observational constraints. - Journal of Wildlife Management 69: 473-482.

Garrard, G. E., Bekessy, S. A., McCarthy, M. A. \& Wintle, B. A. 2008: When have we looked hard enough? A novel method for setting minimum survey effort protocols for flora surveys. - Austral Ecology 33: 986-998.

Gómez-Rodríguez, C., Bustamante, J. \& Díaz-Paniagua, C. 2010: Evidence of hydroperiod shortening in a preserved system of temporary ponds. - Remote Sensing 2: 1439-1462.

Gómez-Rodríguez, C., Bustamante, J., Koponen, S. \& DíazPaniagua, C. 2008: High-resolution remote-sensing data in amphibian studies: identification of breeding sites and contribution to habitat models. - Herpetological Journal 18: 103-113.

Gómez-Rodríguez, C., Díaz-Paniagua, C., Serrano, L., Florencio, M. \& Portheault, A. 2009: Mediterranean temporary ponds as amphibian breeding habitats: The impor- 
tance of preserving pond networks. - Aquatic Ecology 43: 1179-1191.

Gómez-Rodríguez, C., Díaz-Paniagua, C., Bustamante, J., Portheault, A. \& Florencio, M. 2010: Inter-annual variability in amphibian assemblages: Implications for diversity assessment and conservation. - Aquatic Conservation: Marine and Freshwater Ecosystems 20: 668-677.

Gooch, M. M., Heupel, A. M., Price, S. J. \& Dorcas, M. E. 2006: The effects of survey protocol on detection probabilities and site occupancy estimates of summer breeding anurans. - Applied Herpetology 3: 129-142.

Gunzburger, M. S. 2007: Evaluation of seven aquatic sampling methods for amphibians and other aquatic fauna. - Applied Herpetology 4: 47-63.

Heyer, W. R. 1976: Studies in larval amphibian habitat partitioning. - Smithsonian Institution Press, Washington DC.

Heyer, W. R., Donnelly, M. A., McDiarmid, R. W., Hayek, L.-A. C. \& Foster, M. S. 1994: Measuring and monitoring biological diversity. Standard methods for amphibians. - Smithsonian Institution Press, Washington \& London.

Jakob, C., Poizat, G., Veith, M., Seitz, A. \& Crivelli, A. J. 2003: Breeding phenology and larval distribution of amphibians in a Mediterranean pond network with unpredictable hydrology. - Hydrobiologia 499: 51-61.

Junta de Andalucía 2003: Ortofotografía digital de Andalucía. - Junta de Andalucía.

Kery, M., Spillmann, J. H., Truong, C. \& Holderegger, R. 2006: How biased are estimates of extinction probability in revisitation studies? - Journal of Ecology 94: 980-986.

Laan, R. \& Verboom, R. 1990: Effects of pool size and isolation on amphibian communities. - Biological Conservation 54: 251-262.

Lawler, S. P. \& Morin, P. J. 1993: Temporal overlap, competition, and priority effects in larval anurans. - Ecology 74: 174-182.

MacKenzie, D. I. 2005: What are the issues with presenceabsence data for wildlife managers? - Journal of Wildlife Management 69: 849-860.

MacKenzie, D. I. \& Bailey, L. L. 2004: Assessing the fit of site-occupancy models. - Journal of Agricultural Biological and Environmental Statistics 9: 300-318.

MacKenzie, D. I. \& Royle, J. A. 2005: Designing occupancy studies: general advice and allocating survey effort. Journal of Applied Ecology 42: 1105-1114.

MacKenzie, D. I., Nichols, J. D., Lachman, G. B., Droege, S., Royle, J. A. \& Langtimm, C. A. 2002: Estimating site occupancy rates when detection probabilities are less than one. - Ecology 83: 2248-2255.

MacKenzie, D. I., Nicholson, J. D., Royle, J. A., Pollock, K. H., Bailey, L. L. \& Hines, J. E. 2006: Occupancy estimation and modeling. Inferring patterns and dynamics of species occurrence. - Elsevier, Amsterdam.

Mazerolle, M. J., Bailey, L. L., Kendall, W. L., Royle, J. A., Converse, S. J. \& Nichols, J. D. 2007: Making great leaps forward: Accounting for detectability in herpetological field studies. - Journal of Herpetology 41: 672-689.
Paton, P. W. C. \& Crouch, W. B. 2002: Using the phenology of pond-breeding amphibians to develop conservation strategies. - Conservation Biology 16: 194-204.

Pellet, J. \& Schmidt, B. R. 2005: Monitoring distributions using call surveys: estimating site occupancy, detection probabilities and inferring absence. - Biological Conservation 123: 27-35.

Pollock, K. H., Nichols, J. D., Simons, T. R., Farnsworth, G. L., Bailey, L. L. \& Sauer, J. R. 2002: Large scale wildlife monitoring studies: statistical methods for design and analysis. - Environmetrics 13: 105-119.

Rivas-Martínez, S., Costa, M., Castroviejo, S. \& Valdés, E. 1980: Vegetación de Doñana (Huelva, España). Lazaroa 2: 5-189.

Royle, J. A. 2006: Site occupancy models with heterogeneous detection probabilities. - Biometrics 62: 97-102.

Royle, J. A. \& Nichols, J. D. 2003: Estimating abundance from repeated presence-absence data or point counts. Ecology 84: 777-790.

Schmidt, B. R. 2003: Count data, detection probabilities, and the demography, dynamics, distribution, and decline of amphibians - Comptes Rendus Biologies 326: 119-124.

Schmidt, B. R. 2004: Declining amphibian populations: The pitfalls of count data in the study of diversity, distributions, dynamics, and demography. - Herpetological Journal 14: 167-174.

Schmidt, B. R. 2005: Monitoring the distribution of pondbreeding amphibians when species are detected imperfectly. - Aquatic Conservation: Marine and Freshwater Ecosystems 15: 681-692.

Siljeström, P. A., Moreno, A., García, L. V. \& Clemente, L. E. 1994: Doñana National Park (south-west Spain): geomorphological characterization through a soil-vegetation study. - Journal of Arid Environments 26: 315-323.

Snodgrass, J. W., Komoroski, M. J. \& Bryan, A. L. Jr. 2000: Relationships among isolated wetland size, hydroperiod, and amphibian species richness: Implications for wetlands regulations. - Conservation Biology 14: 414-419.

Wellborn, G. A., Skelly, D. K. \& Werner, E. E. 1996: Mechanisms creating community structure across a freshwater habitat gradient. - Annual Review of Ecology and Systematics 27: 337-363.

Wells, K. D. 2007: The ecology and behavior of amphibians. - The University of Chicago Press.

Werner, E. E., Skelly, D. K., Relyea, R. A. \& Yurewicz, K. L. 2007: Amphibian species richness across environmental gradients. - Oikos 116: 1697-1712.

Wiest, J. A. 1982: Anuran succession at temporary ponds in a post oak-savanna region of Texas. - In: Scott, N. J. Jr. (ed.), Herpetological communities: a symposium of the Society for the Study of Amphibians and Reptiles and the Herpetologists' League: 39-47. U.S. Fish and Wildlife Service, Washington, D.C.

Williams, A. K. \& Berkson, J. 2004: Reducing false absences in survey data: Detection probabilities of red-backed salamanders. - Journal of Wildlife Management 68: $418-428$

Yoccoz, N. G., Nichols, J. D. \& Boulinier, T. 2001: Monitoring of biological diversity in space and time. - Trends in Ecology \& Evolution 16: 446-453. 
Appendix 1. Model selection results for each species in 2003 season. $\Psi$ represents the probability of occupancy and $p$ represents the probability of detection. Covariates for each parameter are indicated within parentheses. Dots indicate constants. Parameters manually fixed in a model are specified. $\triangle \mathrm{AIC}_{\mathrm{c}}$ is the difference between the model with the lowest $\mathrm{AIC}_{\mathrm{c}}$ and the given model. Models that did not fit the data are identified with asterisks $\left({ }^{*}\right)$. Param. converg. = parameter convergence.

\begin{tabular}{|c|c|c|c|c|c|c|c|c|}
\hline Species & Model & $\begin{array}{l}\text { Fixed } \\
\text { parameter }\end{array}$ & $-2 \mathrm{LL}$ & k & $\mathrm{AlC}_{\mathrm{c}}$ & $\Delta \mathrm{AIC}_{\mathrm{c}}$ & $\begin{array}{c}\text { Akaike's } \\
\text { weight }(\omega)\end{array}$ & $\begin{array}{l}\text { Param. } \\
\text { converg }\end{array}$ \\
\hline \multirow{6}{*}{$\begin{array}{l}\text { Pelobates } \\
\text { cultripes }\end{array}$} & $\Psi($ area $), p()$. & No & 81.71 & 3 & 89.2 & & 0.384 & $\Psi, p$ \\
\hline & $\Psi(),. p()$. & No & 85.17 & 2 & 89.9 & 0.7 & 0.276 & $\Psi, p$ \\
\hline & $\Psi$ (hydro), $p()$. & No & 83.43 & 3 & 90.9 & 1.7 & 0.163 & $\Psi, p$ \\
\hline & $\Psi(),$.$p (hydro)$ & No & 85.04 & 3 & 92.5 & 3.3 & 0.073 & $\Psi, p$ \\
\hline & $\Psi(),. p($ area $)$ & No & 85.05 & 3 & 92.6 & 3.3 & 0.072 & $\Psi, p$ \\
\hline & $\Psi(),$.$p (month)$ & No & 79.87 & 5 & 94.2 & 4.9 & 0.032 & $\Psi, p$ \\
\hline \multirow{6}{*}{$\begin{array}{l}\text { Discoglossus } \\
\text { galganoi }\end{array}$} & $\Psi(),. p()$. & No & 54.89 & 2 & 59.6 & & 0.450 & $\Psi, p$ \\
\hline & $\Psi$ (area), $p()$. & No & 54.25 & 3 & 61.8 & 2.2 & 0.153 & NO \\
\hline & $\Psi(),$.$p (hydro)$ & No & 54.44 & 3 & 61.9 & 2.3 & 0.139 & $\Psi, p$ \\
\hline & $\Psi(),. p($ area $)$ & No & 54.63 & 3 & 62.1 & 2.5 & 0.127 & $\Psi, p$ \\
\hline & $\Psi$ (hydro), $p()$. & No & 54.79 & 3 & 62.3 & 2.7 & 0.117 & $\Psi, p$ \\
\hline & $\Psi(),$.$p (month)$ & No & 52.39 & 5 & 66.7 & 7.1 & 0.013 & $\Psi, p$ \\
\hline \multirow{6}{*}{$\begin{array}{l}\text { Pelophylax } \\
\text { perezi }\end{array}$} & $\Psi($ area $), p()$. & No & 24.43 & 3 & 31.9 & & 0.949 & NO \\
\hline & $\Psi(),$.$p (hydro)$ & No & 31.39 & 3 & 38.9 & 7.0 & 0.029 & NO \\
\hline & $\Psi$ (hydro), $p()$. & No & 32.24 & 3 & 39.7 & 7.8 & 0.019 & $\Psi, p$ \\
\hline & $\Psi(),$.$p (month)$ & $p_{\mathrm{Feb}}=0$ & 34.49 & 4 & 45.2 & 13.2 & 0.001 & $\Psi, p$ \\
\hline & $\Psi(),. p($ area $)$ & No & 38.70 & 3 & 46.2 & 14.3 & 0.001 & NO \\
\hline & $\Psi(),. p()$. & No & 41.81 & 2 & 46.5 & 14.6 & 0.001 & $\Psi, p$ \\
\hline \multirow{6}{*}{$\begin{array}{l}\text { Hyla } \\
\text { meridionalis }\end{array}$} & $\Psi(),$.$p (month)$ & No & 68.64 & 5 & 82.9 & & 0.999 & $\Psi, p$ \\
\hline & $\Psi(),. p(.)^{*}$ & No & 91.46 & 2 & 96.2 & 13.2 & 0.001 & $\Psi, p$ \\
\hline & $\Psi\left(\right.$ hydro),$p(.)^{*}$ & No & 88.98 & 3 & 96.5 & 13.6 & 0.001 & NO \\
\hline & $\Psi(),. p(\text { area })^{\star}$ & No & 90.16 & 3 & 97.7 & 14.7 & 0.001 & $\Psi, p$ \\
\hline & $\Psi(),. p{\text { (hydro })^{\star}}$ & No & 91.12 & 3 & 98.6 & 15.7 & 0.000 & NO \\
\hline & $\Psi($ area $), p(.)^{*}$ & No & 91.46 & 3 & 99.0 & 16.0 & 0.000 & NO \\
\hline \multirow{6}{*}{$\begin{array}{l}\text { Pleurodeles } \\
\text { waltl }\end{array}$} & $\Psi\left(\right.$ hydro), $p(.)^{\star}$ & No & 85.15 & 3 & 92.7 & & 0.446 & NO \\
\hline & $\Psi(),. p(.)^{*}$ & No & 89.59 & 2 & 94.3 & 1.6 & 0.196 & NO \\
\hline & $\Psi($ area $), p(.)^{*}$ & No & 86.92 & 3 & 94.4 & 1.8 & 0.184 & $\Psi, p$ \\
\hline & $\Psi(),$.$p (hydro) { }^{*}$ & No & 89.23 & 3 & 95.1 & 2.5 & 0.129 & NO \\
\hline & $\Psi(),. p(\text { area })^{*}$ & No & 88.29 & 3 & 95.8 & 3.1 & 0.093 & $\Psi, p$ \\
\hline & $\Psi(),$.$p (month)$ & No & 81.76 & 5 & 96.0 & 3.4 & 0.082 & $\Psi, p$ \\
\hline \multirow{6}{*}{$\begin{array}{l}\text { Triturus } \\
\text { pygmaeus }\end{array}$} & $\Psi(),$.$p (month)$ & $p_{\mathrm{Feb}}=0 ; p_{\mathrm{Apr}}=p_{\text {May }}=1$ & 32.75 & 2 & 37.5 & & 1.000 & $\Psi, p$ \\
\hline & $\Psi(),. p(\text { area })^{\star}$ & No & 88.68 & 3 & 96.2 & 58.7 & 0.000 & $\Psi, p$ \\
\hline & $\Psi($ area $), p(.)^{*}$ & No & 89.01 & 3 & 96.5 & 59.1 & 0.000 & $\Psi, p$ \\
\hline & $\Psi(),. p(.)^{\star}$ & No & 94.99 & 2 & 99.7 & 62.2 & 0.000 & $\Psi, p$ \\
\hline & $\Psi($ hydro $), p(.)^{*}$ & No & 93.20 & 3 & 100.7 & 63.2 & 0.000 & $\Psi, p$ \\
\hline & $\Psi(),. p{\text { (hydro })^{*}}^{*}$ & No & 94.38 & 3 & 101.9 & 64.4 & 0.000 & $\Psi, p$ \\
\hline \multirow{6}{*}{$\begin{array}{l}\text { Lissotriton } \\
\text { boscai }\end{array}$} & $\Psi(),$.$p (month)$ & $p_{\mathrm{Feb}}=p_{\mathrm{Mar}}=0$ & 46.76 & 3 & 54.3 & & 1.000 & $\Psi, p$ \\
\hline & $\Psi(),. p(\text { area })^{\star}$ & No & 74.44 & 3 & 81.9 & 27.7 & 0.000 & NO \\
\hline & $\Psi($ area $), p(.)^{\star}$ & No & 75.86 & 3 & 83.4 & 29.1 & 0.000 & $\Psi, p$ \\
\hline & $\Psi$ (hydro), $p(.)^{*}$ & No & 78.60 & 3 & 86.1 & 31.8 & 0.000 & NO \\
\hline & $\Psi(),$.$p (hydro) { }^{*}$ & No & 80.67 & 3 & 88.2 & 33.9 & 0.000 & NO \\
\hline & $\Psi(),. p(.)^{*}$ & No & 82.99 & 2 & 87.7 & 33.4 & 0.000 & $\Psi, p$ \\
\hline
\end{tabular}


Appendix 2. Model selection results for each species in 2004 season. $\Psi$ represents the probability of occupancy and $p$ represents the probability of detection. Covariates for each parameter are indicated within parentheses. Dots indicate constants. Parameters manually fixed in a model are specified. $\triangle \mathrm{AIC}_{\mathrm{c}}$ is the difference between the model with the lowest $\mathrm{AIC}_{\mathrm{c}}$ and the given model. Models that did not fit the data are identified with asterisks $\left({ }^{*}\right)$. Param. converg. = parameter convergence.

\begin{tabular}{|c|c|c|c|c|c|c|c|c|}
\hline Species & Model & $\begin{array}{l}\text { Fixed } \\
\text { parameter }\end{array}$ & $-2 \mathrm{LL}$ & $k$ & $\mathrm{AlC}_{\mathrm{c}}$ & $\Delta \mathrm{AIC}_{\mathrm{c}}$ & $\begin{array}{l}\text { Akaike's } \\
\text { weight }(\omega)\end{array}$ & $\begin{array}{l}\text { Param. } \\
\text { converg }\end{array}$ \\
\hline \multirow{6}{*}{$\begin{array}{l}\text { Pelobates } \\
\text { cultripes }\end{array}$} & $\Psi(),. p()$. & No & 84.77 & 2 & 89.5 & 0.0 & 0.432 & $\Psi, p$ \\
\hline & $\Psi($ area $), p()$. & No & 83.44 & 3 & 91.0 & 1.5 & 0.202 & $\Psi, p$ \\
\hline & $\Psi(),. p($ area $)$ & No & 84.23 & 3 & 91.8 & 2.3 & 0.136 & $\Psi, p$ \\
\hline & $\Psi(),$.$p (hydro)$ & No & 84.47 & 3 & 92.1 & 2.6 & 0.121 & $\Psi, p$ \\
\hline & $\Psi$ (hydro), $p()$. & No & 84.73 & 3 & 92.3 & 2.8 & 0.106 & $\Psi, p$ \\
\hline & $\Psi(),$.$p (month)$ & No & 80.39 & 6 & 99.4 & 9.9 & 0.003 & $\Psi, p$ \\
\hline \multirow{6}{*}{$\begin{array}{l}\text { Discoglossus } \\
\text { galganoi }\end{array}$} & $\Psi(),$.$p (month)$ & $p_{\mathrm{Jan}}=1 ; p_{\text {Mar }}=p_{\text {Apr }}=p_{\text {May }}=0$ & 20.39 & 2 & 25.1 & & 0.997 & $\Psi, p$ \\
\hline & $\Psi(),. p()$. & No & 33.79 & 2 & 38.5 & 13.4 & 0.001 & $\Psi, p$ \\
\hline & $\Psi(),$.$p (hydro)$ & No & 32.76 & 3 & 40.4 & 15.2 & 0.000 & $\Psi, p$ \\
\hline & $\Psi(),. p($ area $)$ & No & 32.97 & 3 & 40.6 & 15.4 & 0.000 & $\Psi, p$ \\
\hline & $\Psi($ area $), p()$. & No & 22.78 & 3 & 41.4 & 16.2 & 0.000 & $\Psi, p$ \\
\hline & $\Psi$ (hydro), $p()$. & No & 22.79 & 3 & 41.4 & 16.3 & 0.000 & $\Psi, p$ \\
\hline \multirow{6}{*}{$\begin{array}{l}\text { Hyla } \\
\text { meridionalis }\end{array}$} & $\Psi(),$.$p (month)$ & $p_{\mathrm{Jan}}=0$ & 86.78 & 5 & 101.4 & & 0.999 & $\Psi, p$ \\
\hline & $\Psi(),. p(\text { area })^{\star}$ & No & 109.51 & 3 & 117.1 & 15.7 & 0.000 & $\Psi, p$ \\
\hline & $\Psi($ area $), p(.)^{*}$ & No & 109.60 & 3 & 117.2 & 15.8 & 0.000 & NO \\
\hline & $\Psi$ (hydro), $p(.)^{*}$ & No & 110.90 & 3 & 118.5 & 17.1 & 0.000 & NO \\
\hline & $\Psi(),$.$p (hydro ^{*}$ & No & 113.14 & 3 & 120.7 & 19.3 & 0.000 & $\Psi, p$ \\
\hline & $\Psi(),. p(.)^{*}$ & No & 119.44 & 2 & 124.2 & 22.8 & 0.000 & $\Psi, p$ \\
\hline \multirow{6}{*}{$\begin{array}{l}\text { Pleurodeles } \\
\text { walt। }\end{array}$} & $\Psi($ area $), p()$. & No & 74.64 & 3 & 82.2 & & 0.739 & $p$ \\
\hline & $\Psi(),. p()$. & No & 81.36 & 2 & 86.1 & 3.9 & 0.107 & $\Psi, p$ \\
\hline & $\Psi$ (hydro), $p()$. & No & 78.67 & 3 & 86.3 & 4.0 & 0.099 & $\Psi, p$ \\
\hline & $\Psi(),$.$p (hydro)$ & No & 81.10 & 3 & 88.7 & 6.5 & 0.029 & $\Psi, p$ \\
\hline & $\Psi(),. p($ area $)$ & No & 81.30 & 3 & 88.9 & 6.7 & 0.026 & $\Psi, p$ \\
\hline & $\Psi(),$.$p (month)$ & No & 79.70 & 6 & 98.7 & 16.5 & 0.000 & $\Psi, p$ \\
\hline \multirow{6}{*}{$\begin{array}{l}\text { Triturus } \\
\text { pygmaeus }\end{array}$} & $\Psi(),$.$p (month)$ & $p_{\text {Apr }}=1$ & 84.31 & 5 & 98.9 & & 0.896 & $\Psi, p$ \\
\hline & $\Psi(),. p($ area $)$ & No & 95.86 & 3 & 103.5 & 4.5 & 0.093 & $\Psi, p$ \\
\hline & $\Psi(),$.$p (hydro)$ & No & 100.62 & 3 & 108.2 & 9.3 & 0.009 & $\Psi, p$ \\
\hline & $\Psi($ area $), p()$. & No & 103.75 & 3 & 111.4 & 12.4 & 0.002 & $\Psi, p$ \\
\hline & $\Psi$ (hydro), $p()$. & No & 105.32 & 3 & 112.9 & 14.0 & 0.001 & $\Psi, p$ \\
\hline & $\Psi(),. p()$. & No & 110.49 & 2 & 115.2 & 16.3 & 0.000 & $\Psi, p$ \\
\hline \multirow{6}{*}{$\begin{array}{l}\text { Lissotriton } \\
\text { boscai }\end{array}$} & $\Psi(),. p(\text { area })^{*}$ & No & 96.30 & 3 & 103.9 & & 0.414 & $\Psi, p$ \\
\hline & $\Psi($ area $), p(.)^{*}$ & No & 96.58 & 3 & 104.2 & 0.3 & 0.360 & $\Psi, p$ \\
\hline & $\Psi(),$.$p (month) )^{*}$ & No & 88.56 & 6 & 107.5 & 3.6 & 0.070 & $\Psi, p$ \\
\hline & $\Psi$ (hydro), $p(.)^{*}$ & No & 100.16 & 3 & 107.8 & 3.9 & 0.060 & $\Psi, p$ \\
\hline & $\Psi(),. p{\text { (hydro })^{*}}$ & No & 100.16 & 3 & 107.8 & 3.9 & 0.060 & $\Psi, p$ \\
\hline & $\Psi(),. p(.)^{*}$ & No & 103.97 & 2 & 108.7 & 4.8 & 0.037 & $\Psi, p$ \\
\hline
\end{tabular}


Appendix 3. Model selection results for each species in 2006 season. $\Psi$ represents the probability of occupancy and $p$ represents the probability of detection. Covariates for each parameter are indicated within parentheses. Dots indicate constants. Parameters manually fixed in a model are specified. $\triangle \mathrm{AIC}_{\mathrm{c}}$ is the difference between the model with the lowest $\mathrm{AIC}_{\mathrm{c}}$ and the given model. Models that did not fit the data are identified with asterisks $\left(^{\star}\right)$. Param. converg. $=$ parameter convergence.

\begin{tabular}{|c|c|c|c|c|c|c|c|c|}
\hline Species & Model & $\begin{array}{l}\text { Fixed } \\
\text { parameter }\end{array}$ & $-2 \mathrm{LL}$ & $k$ & $\mathrm{AIC}_{\mathrm{c}}$ & $\triangle \mathrm{AIC}_{\mathrm{c}}$ & $\begin{array}{c}\text { Akaike's } \\
\text { weight } \\
(\omega)\end{array}$ & $\begin{array}{l}\text { Param. } \\
\text { converg. }\end{array}$ \\
\hline \multirow{6}{*}{$\begin{array}{l}\text { Bufo } \\
\text { calamita }\end{array}$} & $\Psi(),$.$p (month)$ & $p_{\text {May }}=0$ & 39.19 & 3 & 46.8 & & 0.886 & $\Psi, p$ \\
\hline & $\Psi(),. p()$. & No & 47.76 & 2 & 52.5 & 5.7 & 0.051 & $\Psi, p$ \\
\hline & $\Psi$ (hydro), $p()$. & No & 46.68 & 3 & 54.3 & 7.5 & 0.021 & $p$ \\
\hline & $\Psi(),. p($ area $)$ & No & 47.34 & 3 & 54.9 & 8.2 & 0.015 & $\Psi, p$ \\
\hline & $\Psi(),. p($ hydro $)$ & No & 47.37 & 3 & 55.0 & 8.2 & 0.015 & $p$ \\
\hline & $\Psi($ area $), p()$. & No & 47.75 & 3 & 55.4 & 8.6 & 0.012 & $\Psi, p$ \\
\hline \multirow{6}{*}{$\begin{array}{l}\text { Pelobates } \\
\text { cultripes }\end{array}$} & $\Psi($ area $), p()$. & No & 39.65 & 3 & 47.3 & & 0.458 & $p$ \\
\hline & $\Psi(),$.$p (month)$ & No & 37.75 & 4 & 48.6 & 1.4 & 0.232 & $\Psi, p$ \\
\hline & $\Psi(),. p()$. & No & 44.97 & 2 & 49.7 & 2.5 & 0.133 & $\Psi, p$ \\
\hline & $\Psi$ (hydro), $p()$. & No & 43.52 & 3 & 51.1 & 3.9 & 0.066 & $\Psi, p$ \\
\hline & $\Psi(),. p($ area $)$ & No & 43.68 & 3 & 51.3 & 4.0 & 0.061 & $\Psi, p$ \\
\hline & $\Psi(),$.$p (hydro)$ & No & 44.12 & 3 & 51.7 & 4.5 & 0.049 & $\Psi, p$ \\
\hline \multirow{6}{*}{$\begin{array}{l}\text { Discoglossus } \\
\text { galganoi }\end{array}$} & $\Psi(),$.$p (month)$ & $p_{\text {May }}=0$ & 39.19 & 3 & 46.8 & & 0.618 & $\Psi, p$ \\
\hline & $\Psi(),. p()$. & No & 44.95 & 2 & 49.7 & 2.9 & 0.144 & $\Psi, p$ \\
\hline & $\Psi($ area $), p()$. & No & 43.07 & 3 & 50.7 & 3.9 & 0.089 & $\Psi, p$ \\
\hline & $\Psi$ (hydro), $p()$. & No & 43.78 & 3 & 51.4 & 4.6 & 0.062 & $\Psi, p$ \\
\hline & $\Psi(),$.$p (hydro)$ & No & 44.15 & 3 & 51.8 & 5 & 0.052 & NO \\
\hline & $\Psi(),. p($ area $)$ & No & 44.94 & 3 & 52.5 & 5.7 & 0.035 & $\Psi, p$ \\
\hline \multirow{6}{*}{$\begin{array}{l}\text { Hyla } \\
\text { meridionalis }\end{array}$} & $\Psi$ (hydro), $p()$. & No & 43.17 & 3 & 50.8 & & 0.408 & $\Psi, p$ \\
\hline & $\Psi($ area $), p()$. & No & 44.16 & 3 & 51.8 & 1.0 & 0.249 & $p$ \\
\hline & $\Psi(),. p()$. & No & 47.79 & 2 & 52.5 & 1.8 & 0.168 & $\Psi, p$ \\
\hline & $\Psi(),$.$p (month)$ & No & 43.26 & 4 & 54.1 & 3.3 & 0.077 & $\Psi, p$ \\
\hline & $\Psi(),. p($ area $)$ & No & 47.08 & 3 & 54.7 & 3.9 & 0.058 & $\Psi, p$ \\
\hline & $\Psi(),$.$p (hydro)$ & No & 47.79 & 3 & 55.4 & 4.6 & 0.041 & $\Psi, p$ \\
\hline \multirow{6}{*}{$\begin{array}{l}\text { Pleurodeles } \\
\text { waltl }\end{array}$} & $\Psi(),$.$p (month)$ & $p_{\mathrm{Mar}}=1 ; p_{\mathrm{May}}=0$ & 24.06 & 2 & 28.8 & & 0.857 & $\Psi, p$ \\
\hline & $\Psi(),$.$p (hydro)$ & No & 26.79 & 3 & 34.4 & 5.6 & 0.053 & NO \\
\hline & $\Psi(),. p()$. & No & 29.74 & 2 & 34.5 & 5.7 & 0.050 & $\Psi, p$ \\
\hline & $\Psi(),. p($ area $)$ & No & 29.46 & 3 & 37.1 & 8.3 & 0.014 & $\Psi, p$ \\
\hline & $\Psi$ (hydro), $p()$. & No & 29.49 & 3 & 37.1 & 8.3 & 0.014 & $\Psi, p$ \\
\hline & $\Psi($ area $), p()$. & No & 29.57 & 3 & 37.2 & 8.4 & 0.013 & $\Psi, p$ \\
\hline Triturus & $\Psi(),. p($ area $)$ & No & 39.80 & 3 & 47.4 & & 0.517 & $\Psi, p$ \\
\hline \multirow[t]{5}{*}{ pygmaeus } & $\Psi(),$.$p (hydro)$ & No & 42.30 & 3 & 49.9 & 2.5 & 0.148 & $\Psi, p$ \\
\hline & $\Psi($ area $), p()$. & No & 42.41 & 3 & 50.0 & 2.6 & 0.140 & $\Psi, p$ \\
\hline & $\Psi(),. p()$. & No & 45.30 & 2 & 50.1 & 2.7 & 0.137 & $\Psi, p$ \\
\hline & $\Psi$ (hydro), $p()$. & No & 44.99 & 3 & 52.6 & 5.2 & 0.039 & $\Psi, p$ \\
\hline & $\Psi(),$.$p (month)$ & No & 43.14 & 4 & 54.0 & 6.6 & 0.019 & $\Psi, p$ \\
\hline \multirow{6}{*}{$\begin{array}{l}\text { Lissotriton } \\
\text { boscai }\end{array}$} & $\Psi(),$.$p (month)$ & $p_{\text {Apr }}=1 ; p_{\text {May }}=0$ & 17.84 & 2 & 22.6 & & 0.901 & $\Psi, p$ \\
\hline & $\Psi(),. p()$. & & 24.07 & 2 & 28.8 & 6.2 & 0.040 & $\Psi, p$ \\
\hline & $\Psi$ (hydro), $p()$. & & 22.00 & 3 & 29.6 & 7.0 & 0.027 & $\Psi, p$ \\
\hline & $\Psi(),. p($ area $)$ & & 23.77 & 3 & 31.4 & 8.8 & 0.011 & $\Psi, p$ \\
\hline & $\Psi(),$.$p (hydro)$ & & 23.92 & 3 & 31.5 & 8.9 & 0.010 & $\Psi, p$ \\
\hline & $\Psi($ area $), p()$. & & 23.99 & 3 & 31.6 & 9.0 & 0.010 & $\Psi, p$ \\
\hline
\end{tabular}

